일반논문-10-15-3-05

$$
\begin{gathered}
\text { 이웃 픽셀 값을 고려한 적응적 } 3 \text { 차 보간법 } \\
\text { 이 아 영a^ } \text {, 김 희 창a), 정 제 창a) }
\end{gathered}
$$

\title{
An Adaptive Cubic Interpolation considering Neighbor Pixel Values
}

\author{
Ayeong Lee ${ }^{\mathrm{a}}{ }^{\ddagger}$, HeeChang $\mathrm{Kim}^{\mathrm{a})}$, and Jechang Jeong ${ }^{\mathrm{a})}$ \\ 요 약
}

영상 표시장치의 화소수가 다양화됨에 따라, 영상 보간법은 더욱 중요한 역할을 하게 되었다. 3 차 콘볼루션 보간법(Cubic Convolution Interpolation)은 간단하지만, 적용하는데 제한이 없고, 좋은 성능을 보이기 때문에 널리 쓰이고 있다. 이 논문은 3 차 콘볼루션 보간법을 이용한 적응적 방법을 제안한다. 예측하려는 픽셀의 이웃 화소 값의 차이를 고려해서, 3 차 콘볼루션 보간법 커널에 있는 파 라미터 값을 적응적으로 선택한다.

\begin{abstract}
As the resolution of the image display devices has been diversified, the image interpolation methods has played a more important role. The cubic convolution interpolation method has been widely used because it is simple but it has no limitation of using and a good performance. This paper suggests an adaptive method to the cubic convolution interpolation. Considering the difference of the neighbored pixels values to a prediction pixel, a parameter value in the cubic convolution interpolation kernel is chosen.
\end{abstract}

Keyword: interpolation, cubic convolution interpolation, adaptive interpolation

\section{I. 서 론}

영상보간법은 디지털 영상 처리에서 영상을 확대하거 나 축소하기위해 다양하게 쓰이고 있다. 여기서 영상보 간법은 불연속 샘플로부터, 그것을 연속적인 이벤트로 생각해서 중간 값을 예측하는 것이라고 볼 수 있다 ${ }^{[1]}$. 현 재 다양한 영상 컨텐츠가 방송사나 사용자에 의해서 제 작되고, 영상물은 더욱 일상화되어가고 있다. 이에 따라

a) 한양대학교 전자컴퓨터통신공학부

Department of Electronics Computer Engineering, Hanyang University

* 교신저자 : 이아영(adolsa@naver.com)

· 접수일(2009년12월29일),수정일(2010년3월9일),게재확정일(2010년3월13일)
영상 표시장치의 종류도 다양해지고, 그것의 화소수도 더욱 다양화되어 가고 있다. 이에 따라 영상을 확대하거 나 축소하는 영상보간법은 더욱 중요한 역할을 차지하게 되었다.

주관적인 화질을 향상시키고, 계산량을 줄이기 위해 많 은 보간 방법들이 제안되었다. 가장 간단한 영상보간법은 영차보간법(nearest neighbor interpolation)이다. 이 방법은 간단하지만, 원하지 않는 체커보드 효과(checkerboard effect)가 나타나며, 이것은 확대 계수(magnification factor)가 클수록 두드러진다 ${ }^{[2]}$. 이런 영차보간법의 약점을 극복하기 위해 더 높은 차수의 보간 커널을 기반으로 하는 선형보간 법(bi-linear interpolation)과 3차보간법(bi-cubic interpo- 
lation)방법이 제안되었다. 하지만 이 방법은 영상의 부분적 특질을 고려하지 않기 때문에, 흐려짐 효과(blurring effect) 를 일으키게 된다. 구체적으로는 모서리와 평탄한 부분에 똑같은 알고리즘을 적용하기 때문에 이런 흐려짐 효과가 나타난다.

이런 흐려짐 효과를 줄이기 위해서 여러 가지 보간 방법이 제안되었다. 그중 한 가지는 멀티 해상도 피라미드(multiresolution pyramid) 방법이다. 웨이블릿 구조(wavelet structure)등을 사용하는 방법이 이런 방법에 속한다 ${ }^{[3]}$. 흐려짐 효과를 줄이기 위해 제안된 다른 방법은 지역적인 특질을 찾아, 모서리인지 아닌지 판별하여 그것에 따라 다른 알고 리즘을 적용하는 방법이다 ${ }^{[4]}$. 하지만 지금 언급한 방법들은 복잡도가 높은 단점을 가지고 있다.

최근에는 선형보간법이나 3 차보간법을 기반으로 하여, 이것을 향상시킨 알고리즘들이 제안되고 있다 ${ }^{[5]-[8]}$. 이런 방 법들은 계산이 복잡하지 않으면서도, 좋은 주관적 화질을 얻을 수 있는 특징을 가지고 있다. 특히 확대계수가 2의 거 듭제곱이 아니어도 적용할 수 있다는 장점을 가지고 있다. 기존의 선형보간법이나 3 차보간법에서 지역적인 영상의 특징에 따라 참조할 이웃화소의 위치를 변화를 주거나, 가 중치를 변화시킴으로써 적응적 알고리즘을 얻을 수 있다. Mori는 기존의 3차보간법처럼 정사각형모양의 이웃의 16 개의 화소를 이용하지 않고, 방향성을 고려하여 참조할 화 소의 위치를 선택하는 알고리즘을 제안하였다 ${ }^{[6]}$. 방향성을 고려하는 알고리즘 외에 흐려짐 효과를 줄이기 위해서 영 상의 지역적인 특질 이용하여 가중치에 변화를 주는 여러 가지 방법이 제안되어왔다 ${ }^{[5],[7]-[8]}$. Hwang과 Lee는 이웃화 소의 그래디어트(gradient)를 이용하였고 ${ }^{[5]}$, Hadhoud는 local activity model을 이용하였지만, 보간하고자 하는 화소 의 위치가 원래 샘플링된 위치의 중간에 있지 않으면, 가중 치의 합이 1 이 되지 않는 문제점을 가지고 있다 ${ }^{[7]}$. Han과 Baek는 이웃화소의 기울기값(gradient)과 오목함(concavity) 의 연속성을 고려하였다 ${ }^{[8]}$.

이 논문에서는 기존의 방법들 보다 간단하지만 활용성이 높은 3 차 보간법을 기반으로 하는 보간 방법을 제안한다. 보간하고자 하는 픽셀의 이웃 픽셀 값의 차이를 고려하여 지역적인 특징을 얻고 이에 따라 다른 커널을 사용한다. 다
양한 커널은 3차 보간법 커널 함수의 파라미터 값을 다르게 하여 얻었다. 제안된 방법은 주관적 화질 면에서도, 객관적 인 수치인 peak signal to noise ratio(PSNR)측면에서도 좋 은 결과를 보여주었다.

\section{II. 이론}

\section{3차 콘볼루션 보간법(Cubic convolution interpolation)}

서론에서 설명한 것과 같이 영상보간법은 불연속적으 로 샘플링된 픽셀 값으로부터 연속적인 이벤트를 얻어, 원 이미지에는 없던 중간 값을 예측하는 것으로 볼 수 있 다. 여기서 말하는 연속적인 이벤트는 보간 함수라 하고 그 보간 함수 $g(x)$ 는 다음과 같은 식으로 쓸 수 있다.

$$
g(x)=\sum_{k} c_{k} u\left(\frac{x-x_{k}}{h}\right) .
$$

여기서 $h$ 는 샘플링의 증가(sampling increment)이고, $x_{k}$ 는 보간 노드(interpolation node)이고, $u$ 는 보간 커널, $c_{k}$ 는 원래 이미지가 가지고 있는 픽셀 값을 의미한다. 이처럼 콘 볼루션과 비슷한 오퍼레이션을 사용하여, 불연속 값들로부 터 연속적인 값을 얻는다.

3 차 콘볼루션 보간법에서의 커널은 구간 $(-2,-1),(-1,0)$, $(0,1),(1,2)$ 에서 ' 0 '이 아닌 값으로 정의되며, 나머지 구간 에서는 ' 0 '값을 가진다. 그것을 식으로 쓰면 다음과 같이 쓸 수 있다.

$$
u(s)=\left\{\begin{array}{c}
A_{1}|s|^{3}+B_{1}|s|^{2}+C_{1}|s|+D_{1} 0<|s|<1 \\
A_{2}|s|^{3}+B_{2}|s|^{2}+C_{2}|s|+D_{2} 1<|s|<2 \\
0 \quad 2<|s| .
\end{array}\right.
$$

정수 $s$ 에서의 커널값 $(u(0)=1, u(n)=0, n \neq 0)$, 커 널의 연속성, 그리고 1 차 미분 값의 연속성을 고려하면, 식(2)는 다음과 같이 하나의 미지수만 가진 식으로 쓸 수 있다. 


$$
u(s)= \begin{cases}(a+2)|s|^{3}-(a+3)|s|^{2}+1 & 0<|s|<1 \\ a|s|^{3}-5 a|s|^{2}+8 a|s|-4 a & 1<|s|<2 \\ 0 & 2<|s| .\end{cases}
$$

보간 함수 $g(x)$ 를 테일러 시리즈(Taylor series)의 처음 으로 나오는 3 개의 항만 가진다고 가정하면, 식 (3)에 나오 는 $a$ 는 $a=-\frac{1}{2}$ 로 선택함이 적절함을 알 수 있다.

\section{2. 적응적 3 차 보간법 개괄}

영상의 지역적 특질을 고려하지 않고, $a=-\frac{1}{2}$ 를 사용하 는 것은 문제점이 있다. 값의 변화가 거의 없는 평탄한 지역 은 낮은 주파수성분만을 가진다는 것이고, 테일러 시리즈 의 초기항만 고려해도 된다. 이에 반해 모서리 부분에서는 높은 주파수 성분도 가지는 것이므로, 테일러 시리즈의 많 은 항까지 고려해야 한다. 따라서 테일러 시리즈의 세번째 항까지 고려해서 얻은 상수의 $a$ 값을 사용하기 보다는 지역 적인 특질을 찾아 그에 따라 적절한 $a$ 값을 사용하는 것을 제안하고자 한다. 이 논문에서는 지역적 특징을 얻기 위해 서, 단순히 보간하고자 하는 지점의 이웃한 픽셀의 값만 고 려하였다. 이웃 픽셀 값의 차이에 따라 다음과 같은 $a$ 값을 사용한다.

$$
a= \begin{cases}0 & \text { diff } \leq 2 \\ -\frac{1}{2} & 2<\operatorname{diff} \leq 4 \\ -\frac{3}{4} & 4<\operatorname{diff} \leq 16 \\ -1 & \text { else. }\end{cases}
$$

식 (4)에서 $\operatorname{diff}$ 는 이웃한 픽셀 값의 차이를 뜻한다. 즉, 이웃 픽셀 값의 차이가 작은 평탄한 지역일 때는 $a$ 값을 ' 0 ' 으로 사용하고, 픽셀 값의 차이가 클수록 절대 값이 큰 $a$ 값 을 사용한다.

\section{3. 적응적 3차 보간법 해석}

앞에서 설명한대로 공간영역에서 보간함수는 다음과 같
이 쓸 수 있다.

$$
g(x)=\sum_{k} c_{k} u\left(\frac{x-x_{k}}{h}\right) .
$$

식 (5)에 나와 있는 공간영역에서의 커널을 퓨리에 변환 (Fourier transform)을 이용해서 주파수영역의 함수로 바꾸 면 식 (6)과 같다.

$$
G(\omega)=\sum_{k} c_{k} e^{-j \omega x_{k}} h U(\omega h)
$$

여기서 식(7)과 같은 퓨리에 변환을 이용하였다.

$$
G(\omega)=\frac{1}{\sqrt{2 \pi}} \int_{-\infty}^{+\infty} g(x) e^{-j \omega x} d x
$$

식 (6)에서 $U(\omega)$ 는 다음과 같다.

$$
U(\omega)=\frac{1}{\sqrt{2 \pi}} \int_{-\infty}^{+\infty} u(x) e^{-j \omega x} d x
$$

식 (6)은 다음과 같이 해석될 수 있다. $c_{k} e^{-j \omega x_{k}}$ 의 누적 합은 보간 노드에 대한 불연속 퓨리에 변환(discrete Fourier transform)으로 볼 수 있고 이것에 곱해져 있는 $U(\omega h)$ 는 저주파만 통과시키는 스무딩 필터(smoothing filter)로 생각 할 수 있다. 따라서 보간 커널을 주파수 영역에서 보면, 그 보간법의 특징을 파악할 수 있다.

이상적인 보간 커널함수는 $\operatorname{sinc}$ 함수이다. 왜냐하면 이 $\operatorname{sinc}$ 함수를 주파수영역에서 보면, 주파수 구간 $(-0.5,0.5)$ 에 서 ' 1 '의 값을 가지고, 나머지 구간에서는 ' 0 '의 값을 가지 기 때문이다. 이상적이나, 실제적으로 적용이 불가능하다. 하지만 실제로 적용하는 보간 커널이 얼마나 이 $\operatorname{sinc}$ 함수에 가까운지 살펴봄으로써, 적절한 보간을 하는지 따져 볼 수 있다.

그림 1 은 $a$ 값에 따른 커널을 공간영역과 주파수영역에 서 보여주고 있다. 여기서 주파수의 단위는 각주파수, $\omega$ 가 아닌 주파수, $f$ 를 사용하였다. 그림에서 보면, $a$ 값의 절대 

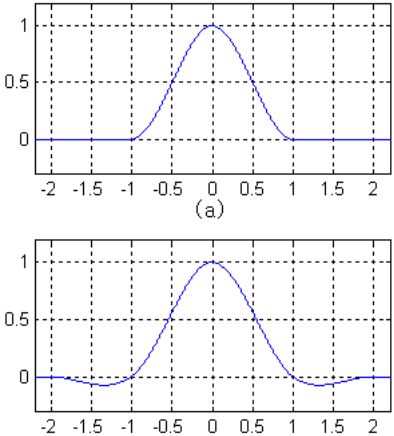

(d)
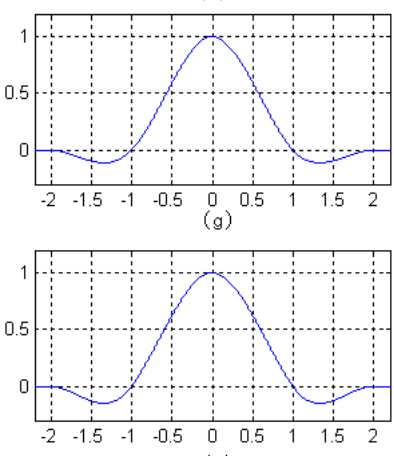

(j)
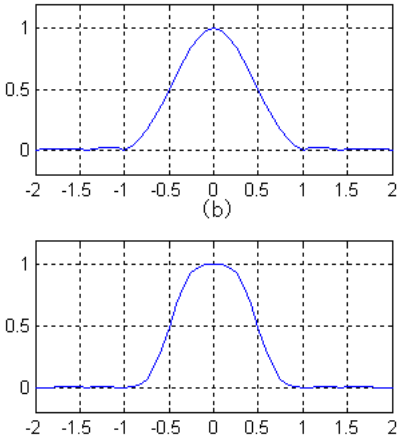

(e)
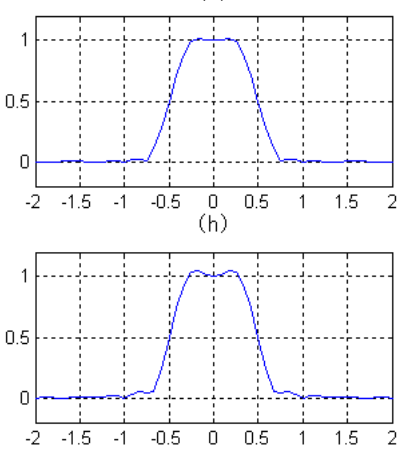

(k)
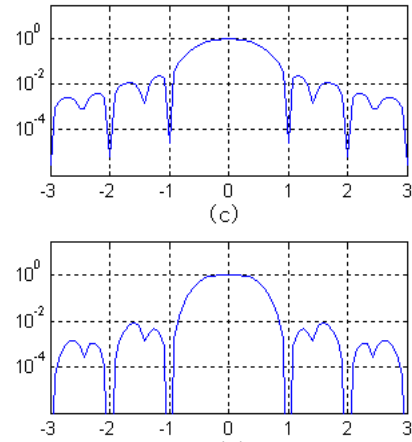

(f)
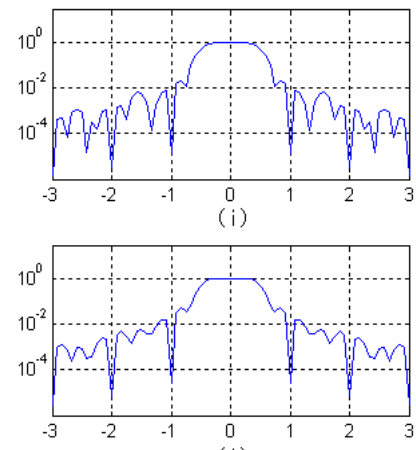

(1)

그림 1. 보간 커널 $a=0$ 일 때, (a) $u(x)$ (b) $U(f)$ 의 크기 (c) 로그스케일의 $U(f)$ 크기 $a=-0.5$ 일 때, (d) $u(x)$ (e) $U(f)$ 의 크기 (f) 로그스케일의 $U(f)$ 의 크기 $a=-0.75$ 일 때, $(\mathrm{g}) u(x)$ (h) $U(f)$ 의 크기 (i) 로그스케일의 $U(f)$ 의 크기 a=-1일 때, (j) $u(x)$ (k) $U(f)$ 의 크기 (l) 로그스케일의 $U(f)$ 의 크기 Fig. 1. Interpolation kernels, when $a=0$ (a) $u(x)$ (b) Magnitude of $U(f)$ (c) Magnitude of $U(f)$ in log scale, when $a=-0.5$ (d) $u(x)$ (e) Magnitude of $U(f)$ (f) Magnitude of $U(f)$ in $\log$ scale, when $a=-0.75(\mathrm{~g}) u(x)$ (h) Magnitude of $U(f)$ (i) Magnitude of $U(f)$ in log scale, when a=-1 (j) $u(x)$ (k) Magnitude of $U(f)$ (I) Magnitude of $U(f)$ in log scale

값 크기가 클수록, 높은 주파수를 더 많이 통과시킨다는 것 을 알 수 있다. 즉, 이웃 픽셀간의 차이가 클 때, 절대값 크 기가 큰 $a$ 값을 씀으로써 높은 주파수를 통과시키는 보간 필터를 사용하는 것이다.

\section{III. 결과}

\section{1. 객관적 화질 비교}

객관적인 화질 비교를 위해서 제안된 알고리즘을 사용하 여 보간한 영상의 PSNR을 0차 보간, 선형보간, 3 차보간,
Han의 3차보간[8], Mori의 3차보간[6]과 비교하였다. 512x 512 영상을 다운 샘플링하여, $170 \times 170$ 영상을 얻은 후, 그것 을 보간하여 다시 $512 \times 512$ 영상을 얻어, 원본과 비교하였 다. 다운 샘플링 방법으로는 매틀랩의 디폴트 설정으로 선 형보간법을 사용하였다. 따라서, $11 \mathrm{by} 11$ 의 저역통과필터를 사용하였다. 결과는 표 1 과 같다.

표 1 에는 0 차보간, 선형보간, 3 차보간, $\mathrm{Han}$ 의 3 차보간, Mori의 3차보간, 제안된 3차보간의 PSNR이 차례로 나와 있다. 평균 PSNR을 보면, 다른 보간법보다 향상되었음을 알 수 있다. 기존의 3 차 보간법보다는 $0.25 \mathrm{~dB}$ 상승했다. 그 리고 9가지의 테스트 영상 모두에서 PSNR이 가장 좋은 것 은 제안된 보간법임을 볼 수 있다. 특히, 모서리가 많은 영 
표 1. PSNR 비교

Table 1. PSNR Comparison

\begin{tabular}{|c|c|c|c|c|c|c|}
\hline & nearest & bilinear & bicubic & Han's cubic[8] & Mori's cubic[6] & Proposed \\
\hline airplane & 25.09 & 27.26 & 28.08 & 28.18 & 27.97 & 28.39 \\
\hline boat & 25.64 & 26.96 & 27.70 & 27.87 & 27.64 & 27.91 \\
\hline butterfly & 23.54 & 25.29 & 26.28 & 26.42 & 26.29 & 26.69 \\
\hline couple & 25.13 & 26.03 & 26.59 & 26.67 & 26.53 & 26.69 \\
\hline finger & 21.67 & 22.89 & 23.97 & 24.28 & 23.70 & 24.31 \\
\hline girl & 28.14 & 30.79 & 31.93 & 32.07 & 31.88 & 32.19 \\
\hline lena & 27.48 & 29.38 & 30.31 & 30.43 & 30.30 & 30.56 \\
\hline peppers & 26.19 & 28.94 & 29.62 & 29.60 & 29.61 & 29.87 \\
\hline zelda & 30.77 & 33.59 & 34.51 & 34.58 & 34.42 & 34.69 \\
\hline 평균 & 25.96 & 27.90 & 28.78 & 28.90 & 28.71 & 29.03 \\
\hline
\end{tabular}

상에서 적응적 알고리즘이 더 좋은 성능을 보임도 알 수 있다.

\section{2. 주관적 화질 비교}

그림 2 는 각각의 알고리즘으로 4 배로 확대된 butterfly의 부분영상 이다. 그림을 살펴보면 제안된 적응적 3 차 보간법 은 체커보드 효과도 없고, 모서리에서 흐려짐 현상도 적은 것을 볼 수 있다.

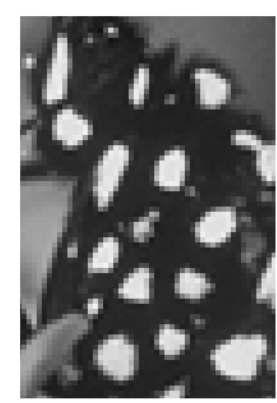

(a)

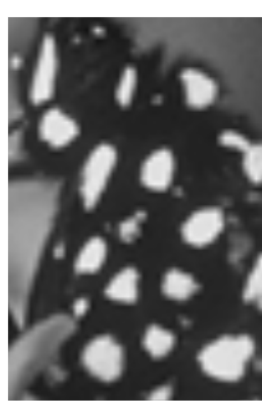

(b)

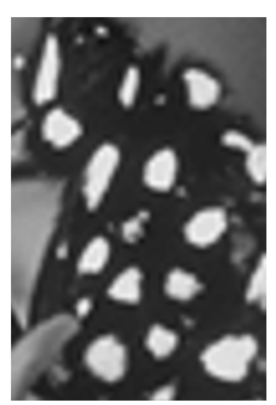

(c)

\section{IV. 결 론}

3 차 보간법은 확대 계수의 제한이 없고, 간단하지만 좋은 성능을 보이므로, 여전히 많이 쓰이고 있다. 하지만, 이것의 문제점은 모서리에서의 흐려짐 현상이 발생한다는 것이다. 제안하는 적응적 3 차 보간법은 영상의 지역적인 특질을 간 단한 방법으로 고려해 커널을 선택함으로써 이런 문제점을 개선시켰다. 주관적으로도, 객관적인 수치로도 화질이 향 상됨을 볼 수 있었다.

그림 2. (a) 0 차 보간법에 의해 4 배 확대된 Butterfly 부분 영상, (b) 선형보간법에 의해 4 배 확대된 Butterfly 부분 영상, (c) 3 차 보간법에 의해 4 배 확대된 Butterfly 부분 영상, (d)Han의 3차 보간법에 의해 4배 확대된 Butterfly 부분 영상[8],(e) Mori의 3차 보간법에 의해 4배 확대된 Butterfly 부분 영상[6], (f) 제안된 적응적 3 차 보간법에 의해 4 배 확대된 Butterfly 부분 영상

Fig. 2. a part of the magnified butterfly image by (a) nearest, (b) bilinear, (c) bicubic, (d) Han's bicubic[8], (e)Mori's bicubic[6] and (f) proposed adaptive bicubic 


\section{참 고 문 헌}

[1] R.G. Keys, "Cubic Convolution Interpolation for Digital Image Processing," IEEE Trans. Acoust. Speech Signal Process, ASSP-29, No. 6, pp. 1153-1160, Dec. 1981

[2] T. M. Lehmann, C. Gonner and K. Spitzer, "Survey: Interpolation Methods in Medical Image Processing," IEEE Trans. Medical Imaging, Vol. 18, No. 11, pp. 1049-1073, Nov. 1999

[3] N. Nguyen and P. Milanfar, "A Wavelet-Based InterpolationRestoration Method for Super-resolution," Circuits Systems Signal Process, Vol. 19, No. 4, pp. 321-338, 2000

[4] X. Li and M. T. Orchard, "New Edge-Directed Interpolation", IEEE Trans. Image Processing, Vol. 10, No. 10, pp. 1521-1527, 2001,
[5] J. W. Hwang and H. S. Lee. "Adaptive Image Interpolation Based on Local Gradient Features," IEEE Signal Processing Letters, Vol. 11, No. 3, pp. 359-362, 2004

[6] T. Mori, K. Kameyama, Y. Ohmiya, J. Lee and K. Toraichi, "Image Resolution Conversion Based on an Edge-Adaptive Interpolation Kernel," IEEE Pacific Rim Conference on Digital Object Identifier, pp. 497-500, 2007

[7] Hadhoud, M. M., Dessouky, M. I., et al, "Adaptive Image Interpolation Based on Local Activity Levels," Proceedings of the 20th National Radio Science Conference, C4 1-8, 2003

[8] Jong-ki Han and Seung-Ung Baek, "Parametric cubic convolution scaler for enlargement and reduction of image," Consumer Electronics, IEEE Transactions, 46(2), pp. 247-256, 2000

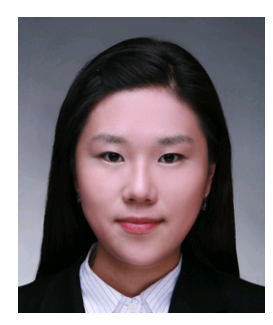

\section{이 아 영}

- 2008년 2월 : 한양대학교 전자전기컴퓨터공학부 졸업 (공학사)

- 2008년 8월 현재: 한양대학교 전자컴퓨터통신공학과 석사과정

- 주관심분야 : Image processing, Image Enhancement

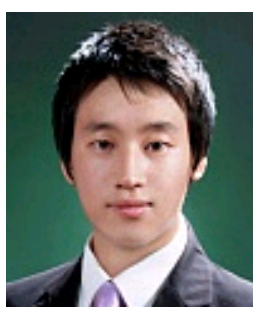

김 희 창

- 2008년 2월 : 한양대학교 전자전기컴퓨터공학부 졸업 (공학사)

- 2010년 2월 : 한양대학교 전자컴퓨터통신공학과 졸업 (공학석사)

- 2010년 2월 현재: Chip\&Media 연구원

- 주관심분야 : Image Processing, Image Enhancement

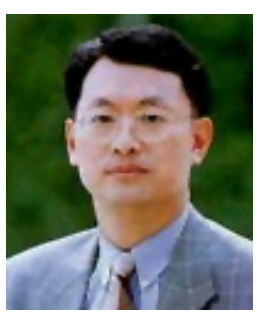

\section{정 제 창}

- 1980년 2월 : 서울대학교 전자공학과 졸업 (공학사)

- 1982년 2월 : KAIST 전기전자공학과 졸업 (공학석사)

- 1990년 3월 : 미국 Univ. of Michigan 전기공학과 졸업 (공학박사)

- 1982년 2월 1986년 7월 : KBS 기술연구소 연구원 (디지털 TV 및 뉴미디어 연구)

- 1990년 8월 1991년 1월 : 미국 Univ. of Michigan 전기공학과 연구교수

- 1991년 1월 1995년 2월 : 삼성전자 멀티미디어 연구소 (MPEG, HDTV 및 멀티미디어 연구)

- 1995년 3월 현재 : 한양대학교 전자전기컴퓨터공학부 교수 (영상통신 및 신호처리 연구실)

- 1998년 11월 27일 : 과학기술자상 수상

- 1998년 12월 31일 : 정보통신부장관상 표창

- 주관심분야 : 영상처리 및 영상압축 